\title{
Active thermal characterization of building wall layers using inverse method
}

\author{
by E. Biteau, F. Brachelet, D. Defer and L. Zalewski \\ Univ. Artois, ULR 4515, Laboratoire de Génie Civil et géo-Environnement (LGCgE), Béthune, F-62400, France \\ franck.brachelet@univ-artois.fr
}

\begin{abstract}
This article presents an active method of building walls thermal characterization. A thermal stimulation is applied by a heating blanket on one side of the wall. Temperatures and injected heat flux evolutions are recorded by a data logger on the front face and the temperature by an infrared camera on the back face. Those signals are then processed by an inverse method which allows the determination of the thermal conductivity and the specific heat of each wall layers as well as the Newton's coefficient, knowing their thicknesses. Different types of stimulation waveforms are tested and the associated uncertainties are determined.
\end{abstract}

\section{Introduction}

Current environmental and economic concerns aim to reduce energy consumption. It turns out that buildings causing a large part of consumption have great potential for reduction. The building envelope renovation is the first way to improve the energy performance of buildings. In an improvement approach of existing buildings, taking into account the thermal behavior of a wall is not easy due to the unawareness of its real thermophysical properties. These parameters are however predominant for the economic optimization phase of renovation operations or to verify its real performance. It therefore appears important to be able to characterize the walls of buildings in situ [1,2]. Therefore, we present in this article the development of a non-destructive testing [3] method allowing the in situ thermal characterization of the walls.

\section{Experimental set up}

The experimental set up developed [4] to heat the wall is showed on figure 1. It is based on a heating blanket insulated on its back face with styrofoam. The heating waveform is generated by a function generator and a power supply. A heat fluxmeter and thermocouples are placed between the blanket and the wall in order to measure the conduction heat transfer at the interface. These data are recorded by a data logger. For the first tests, heat flux was also measure on the back face in order to validate the method, but it was removed for the further tests and the temperature was only measure with the infrared camera.

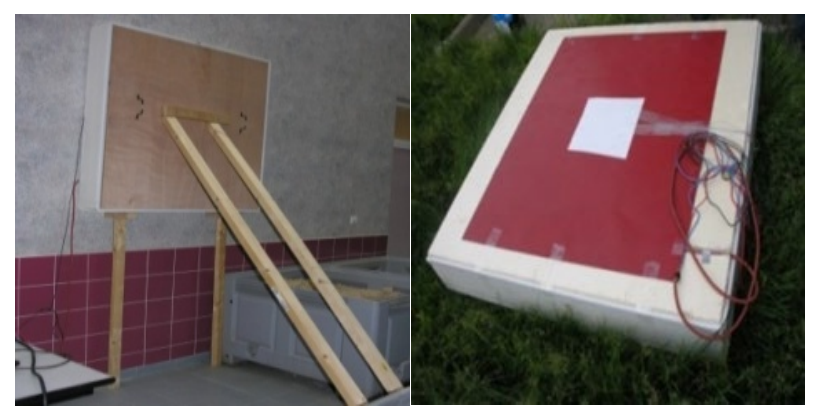

Fig. 1. Experimental heating set up

\section{Tests performed on walls}

In a first step, we heated a test wall which had been previously fitted with heat fluxmeters and temperature sensors. The heat flux and temperatures were recorded for several days using a data logger. An inverse identification method was developed to determine thermophysical parameters of the wall. The numerical model was written with the finite-difference modelling method. Knowing the indoor and outdoor surface temperatures and the inlet and outlet heat flux, the thermophysical parameters of the wall could be determined. This first step of the study allowed to validate the inverse method for a conduction heat transfer conditions. Then, in a second step, we only used an infrared camera to measure the outdoor surface temperature. From the inlet flux, the indoor surface temperature, and the compensated outdoor 
temperature we computed the thermophysical parameters, thermal conductivity and specific heat, of the wall layers with an inverse identification method.

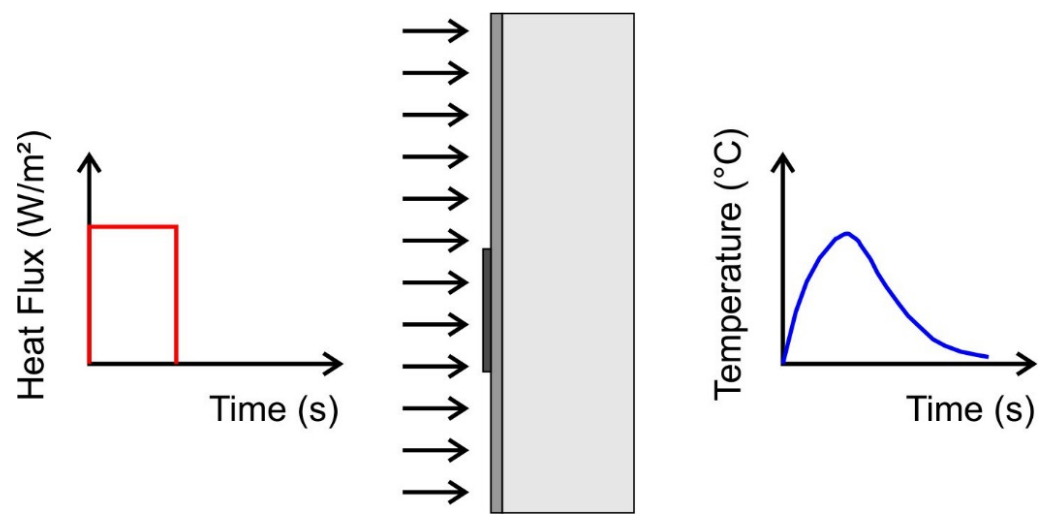

Fig. 2. Waveform example

Knowing thicknesses, the study extended to bi-layer walls made with plaster and concrete blocks, also allowed the identification of the thermophysical characteristics. A sensitivity study allows the evaluation of the uncertainties of each experimental component. Several thermal stimulation waveforms have been studied to determine their influences on the results accuracy.

\section{Conclusion}

Thanks to the active approach of the method, the test time is shortened compared to traditional methods. Moreover, this study showed that this experimental heating setup was easily transportable, well suited to the characterization of light walls and that it allowed an accurate determination of the thermophysical characteristics of the wall layers.

\section{REFERENCES}

[1] ISO 9869-1:2014 — Thermal insulation — Building elements — In-situ measurement of thermal resistance and thermal transmittance - Part 1: Heat flow meter method

[2] ISO 9869-2:2018 Thermal insulation - Building elements — In-situ measurement of thermal resistance and thermal transmittance - Part 2: Infrared method for frame structure dwelling

[3] X. P. Maldague, "Theory and Practice of Infrared Technology for Nondestructive Testing", Ed. Wiley

[4] K. Chaffar, A. Chauchois, D. Defer, L. Zalewski, "Thermal characterization of homogeneous walls using inverse method", Energy and Buildings, 2014, Vol. 78, pages 248-255. 